\title{
THE INFLUENCE OF PLAIN LANGUAGE AND STRUCTURE ON THE READABILITY OF CONTRACTS
}

\section{Introduction}

Contracts form an integral part of our existence, both in our work and personal environments. They are an unavoidable consequence of our participation in the commercial world. As such they are important since they will determine the distribution of wealth and power in society.

South African law has always stuck religiously to the principles of freedom of contract and pacta sunt servanda. That is to say, everyone should have the utmost freedom to enter into contracts with whomever they please and once that agreement has been struck it must be adhered to. Through the application of these principles the law of contract obtained a high degree of certainty which is important for the parties to a contract because they know what their rights and obligations are. Furthermore they are safe in the knowledge that the contract is enforceable.

While this may be an ideal situation we do not live in an ideal world. A large percentage of our society has had little contractual experience and even those that have are still regularly involved in contacts over which they have no control. Whilst consumers supposedly have freedom to contract, they very often have no leverage to negotiate the terms of the contract since a business will often make use of a standard form contract. As a consequence of this lack of bargaining power, consumers entering into contracts may not bother to read the terms since they are bound by them no matter what. Another reason is that they may be drafted and set out in such a way as to dissuade consumers from reading them.

\section{The use of standard-form contracts}

Standard-form contracts refer to those contracts whose conditions are contained in a standardized document which was drafted in advance by one of the parties and the contract is open to acceptance in that form alone (Aronstam Consumer Protection, Freedom of Contract and the Law (1979) 16-17; and Van der Merwe, van Huyssteen, Reinecke and Lubbe Contract: General Principles (1993) 225). Aronstam (18-19) identifies three possible meanings of the term standard-form contract:

(a) Where a precedent or model specimen exists which can be used as a basis for drafting a contract which may later be altered or adapted by the contracting parties.

(b) Where a contract is accepted in a trade in a standard-form and the rights and duties of the parties are determined before the contract has been 
concluded (Eiselen "Die Standaardbedingprobleem: Ekonomiese Magsmisbruik, Verbruikersvraagstuk of Probleem in Eie Reg?" 1988 De Jure 254 (hereinafter "Eiselen (a)").

(c) Where legislation prescribes certain terms which must form part of a contract and the rest is left to the contracting party's discretion.

The common law stresses that there must be agreement between the contracting parties which suggests that the parties negotiate every term included in their agreement (Woker "Business Practice Statutes and Consumer Protection" in McQuoid-Mason (ed) Consumer Law in South Africa (1997) 27.) In practice this does not occur as many institutions in the private sector make use of standard-form contracts. Standard-form contracts only gained acceptance and general use in the nineteenth century during the laissez-faire economic era. However, the rules established for the law of contract developed before the advent of standard-form contracts and centred on the principle of a negotiated agreement (Eiselen (a) 254; and Woker 27). Individual bargaining between the parties was the cornerstone of the contractual mechanism and a means of ensuring contractual justice. Standard-form contracts do not correspond with this view of the contractual relationship since the aspect of negotiation is absent (Eiselen (a) 254). Kahn (General Principles of Contract 2ed (1988) 34) describes a standard-form contract as a "depersonalised contract which is a one-sided product of an economically superior party imposing rules that favour him, especially exemption from liability provisions".

Eiselen ("Die Standaardbedingprobleem: Ekonomiese Magsmisbruik, Verbruikersvraagstuk of Probleem in Eie Reg?" (vervolg) 1989 De Jure 44 53 (hereinafter "Eiselen (b)") indicates that it is the mechanism of unilateral drafting of standard terms and the manner in which they are included in standard-form contracts that is the real foundation of the problem of standard-form contracts. These terms and conditions of the contract are crucial for the consumer and business as they determine the legal position of the parties to the contract, the rights and obligations of the parties and often the consequences of a breach of the terms and conditions and it is thus very important for consumers to read these documents (Van den Bergh Readable Consumer Contracts (1985) 1). However, the language used and structure of the contract often owe more to financial imperatives rather than to legitimate contractual principles (a decision on the layout of the contract may be determined by cost implications for example).

\section{$3 \quad$ Language and structure of standard-form contracts}

As stated earlier, consumers will seldom read these important terms, which may appear in the actual document they sign, on the reverse side of the document they sign or, on occasion, in a separate document which is given to them either when they conclude the contract or at a later stage. A variety of reasons for this can be put forward: Among others, consumers are commonly more interested in obtaining the goods rather than acknowledging the consequences of the purchase; they may feel that they trust the business that they are dealing with to deal honestly, or they may simply believe that they will not be able to understand the terms and conditions so 
simply do not bother to read them. Van den Bergh (see below for an explanation of these concepts) proposes that one of the reasons may be that the terms and conditions are written in a manner which is unattractive and unintelligible to consumers. By this it is meant that the contracts are not readable both typographically and linguistically.

With the introduction of two very important pieces of consumer legislation, namely the National Credit Act 34 of 2005 (hereinafter "the NCA") and the Consumer Protection Act 68 of 2008 (hereinafter "the CPA", which is due to come into operation for consumers on 1 April 2011) legislators have given effect to the widely held perception of unreadable contracts by including a section compelling drafters to write in "plain language" (s 64 of the National Credit Act and s 22 of the Consumer Protection Act). Section 64 of the NCA holds as follows:

"(1) The producer of a document that is required to be delivered to a consumer in terms of this Act must provide that document-

(a) in the prescribed form, if any, for that document; or

(b) in plain language, if no form has been prescribed for that document.

(2) For the purposes of this Act, a document is in plain language if it is reasonable to conclude that an ordinary consumer of the class of persons for whom the document is intended, with average literacy skills and minimal credit experience, could be expected to understand the content, significance, and import of the document without undue effort, having regard to -

(a) the context, comprehensiveness and consistency of the document;

(b) the organisation, form and style of the document;

(c) the vocabulary, usage and sentence structure of the text; and

(d) the use of any illustrations, examples, headings, or other aids to reading and understanding."

Section 22 contains the same wording except it refers not only to the "document" which a credit provider must provide consumers, but also to any "notice or visual presentation" provided or displayed to consumers. This section has a far wider signification as it refers to any writing which is made available through any manner to a consumer. It is not only a contract that is concluded with the consumer but also advertising material and, more importantly, any notices displayed to a consumer. These include indemnity notices which a business may erect, and as such is a very important protection for consumers.

In section $64(3)$ of the NCA and section 22(3) of the CPA provision is made for the publishing of guidelines (by the National Credit Regulator in the case of the NCA and the Commission in the case of the CPA) for methods of assessing whether a document, notice of visual representation satisfies the requirements of subsection 1 (b), although no such guidelines have been published. Even prior to the introduction of the NCA and CPA, the courts were increasingly considering the layout of a contract into account when evaluating whether or not an error is iustus (see amongst others Keens Group Co (Pty) Ltd v Lötter 19891 SA 585 (C); Diners Club SA (Pty) Ltd v Thorburn 19902 SA 870 (C); Diners Club SA (Pty) Ltd v Livingstone 19954 SA 493 (W); Roomer v Wedge Steel (Pty) Ltd 19981 SA 538 (N); Langeveld v Union Finance Holdings (Pty) Ltd 20074 SA 572 (WLD); and Mercurius 
Motors $v$ Lopez 20083 SA 572 (SCA)). Many of the factors which the courts considered are mentioned in subsection 2 in sub paragraphs (a) to (d) of the Acts. These try to offer some assistance in regard to guidelines for drafters by mentioning a number of factors which can be considered when evaluating a contract. The relevant sections of the two Acts also refer to an "ordinary consumer" with "average literacy skills" which are undefined concepts and, given the literacy rate in South Africa, one would expect to be interpreted at a very basic level (see Viljoen and Nienaber A Plain Legal Language for a New Democracy (2001) 58-59 on multilingualism and literacy).

This note does not propose that, by altering the structure of the standardform contracts, the problems they pose will be solved. Simplifying the structure and complying with the NCA and CPA may, however, contribute to the solution of the problems caused by the use of standard-form contracts, more specifically to render them in language that will be accessible to the ordinary consumer of average literacy skills.

This note aims to identify common features which are used in contracts that may create unnecessary difficulties for consumers when they attempt to read a contract. For purposes of this note, examples have been taken from the standard-form contract which banks use to regulate credit card use. Credit card contracts were chosen because they have become a popular form of payment and the terms are made available to an applicant on the reverse side of the application form when application is made. Thus, they are readily available to the consumer. Another reason is that banks have, on their own initiative, (the Banking Association of South Africa adopted a Code of Banking Practice in 2000) undertaken a process of simplification which, in most cases, provides an example of what is discussed below.

The factors will be considered under two headings namely, typographic readability, which refers to the visual presentation of a printed contract and linguistic readability which refers to the syntactic formulation of the terms contained in the contract.

\section{$4 \quad$ Typographic readability}

Quite often the contract is physically illegible because of the font size and the type of font that is used. The colours utilized, both of the paper and the print, may be dull and unattractive and may dissuade somebody from attempting to read it. This is in stark contrast to any advertising which the business may do to attract the consumers' attention. When advertising, a business makes use of a variety of colours, print sizes and layouts in order to ensure they attract the attention of the consumer. The NCA (s 64(2)(b)) and CPA (s 22(2)(b)) make reference to the "organisation, form and style of the document, notice or visual representation" which would cover the points under typographic readability. In analysing the typographic readability of a standard-form contract, this note considers the font size and colour, layout of the contract and headings. These are factors which are identified by Van den Bergh (1) as playing the greatest role in the readability of a standardform contract. 


\section{Font}

\section{Font size}

The font size more than any other factor may deter a consumer from reading a contract. The majority of writing which a consumer will come across in an everyday situation is printed in at least size ten font. Most standard-form contracts will use a smaller size font and all the conditions of use are typed in a size seven or eight font. For example Standard Bank:

"The card is issued and the card facilities are granted subject to the following terms and conditions ('conditions'). The abbreviations and definitions will form part of the conditions. The headings are for convenience only and will not be used in the interpretation of the conditions."

The argument is advanced that the use of such small print reduces the number of pages used for contract. Firstly, this saves a business, and supposedly the consumer, money because less paper is used and secondly, consumers are more likely to read a single page of conditions than multiple pages. This argument is valid from a cost-saving point but the use of such a small font does make reading difficult, if not impossible. In Diners Club SA v Livingstone (supra) it was held:

"At the back of the enrolment form are a series of conditions in incredibly small print, not designed to be read without the aid of magnifying equipment" (495I).

This is an apt description of the font size of most standard-form contracts. The minimum font size which is recommended for use is size eight (Van den Bergh 30; Dick "Plain English in Legal Drafting" 1980 xviii(3) Alberta Law Review 510-511). It is also preferable to use fewer printing types and sizes within the contract as this could make reading extremely difficult and possibly mislead the consumer as to the importance of certain clauses (Van den Bergh 30).

\section{Font colour}

This is not a major factor affecting the readability of standard-form contracts but may, in a small way, contribute to making them more attractive to the consumer. By using colours other than the standard black-on-white, the contract may be more visually appealing and possibly encourage the consumer to read the contents. First National Bank, Standard Bank and ABSA use blue-on-white, while Nedbank, Diners Club and American Express use the traditional black-on-white.

\section{Layout of the form}

This refers to the way in which the printing is arranged on the pages and the positioning of important clauses. Dick (1980 xviii(3) Alberta Law Review 510) states that the conditions should rather be placed in two columns on a page rather than long sentences stretching from one side of the page to the other. The NCA and CPA cover this under sections 64(2)(b) and s22(2)(b) 
respectively when they refer to the "organisation, form and style".

Standard Bank and ABSA make use of two columns on their A4 size application forms. The other card issuers use forms which are concertinaed so that the writing stretches from one side to the other, but is still short enough to match the size of a column.

The positioning of important or unusual clauses within the contract is also a problem in standard-form contracts. In the cases referred to earlier, the court has held that the layout of a form and the positioning of important clauses may lead to mistakes and cause misrepresentations (see also Brink v Humphries \& Jewell (Pty) Ltd 20052 SA 419 (SCA) 425-426; and Royal Canin South Africa (Pty) Ltd v Cooper 20086 SA 644 (SECLD) 646-647). Businesses have the opportunity to draft the standard-form contract and they may do so in a manner that deceives the consumer as to the nature of the document they are signing. In Diners Club SA v Livingstone (supra) the court held:

"The whole get-up of the enrolment form is such as to mislead a person into thinking that only the company was being considered for enrolment" (495G).

They are further aware of clauses which are more important than others and they make no attempt whatsoever to highlight these for the benefit of the contractant. In Keens Group v Lötter (supra) the court emphasized this:

"While not in a particularly inconspicuous place that obligation is not made particularly conspicuous either. It appears in the same type style and size as the rest of the document" (590F).

The ease with which this can be solved was duly pointed out in Roomer $v$ Wedge Steel (Pty) Ltd (supra) when it was held:

"In casu the respondent effectively guarded against the possibility that it would be overlooked amongst the other clauses of the credit application by heading the document 'Contract of sale and deed of suretyship' and by printing the suretyship undertaking in heavy type" (543G-I).

In summary then, the layout of a form (contract) may have a substantial impact on the readability of a contract and more importantly the content of such contract. This was emphasized in Diners Club SA (Pty) Ltd v Thorburn (supra), where Burger J held:

"I consider it sound in principle that the party who drafts a contractual document would be blameworthy if he did so in such a way as to turn it into a trap containing onerous clauses which would not reasonably be expected by the other party. A signatory can be misled by the form and appearance of the document itself just as much as by a prior advertisement or representation" (875B-C).

\section{Headings}

Headings of contracts are only used as a secondary source in interpretation and will be disregarded if the terms under such heading are clear. This may be unfair since a heading may give an indication of the content of a contract as was pointed out in Keens Group (Pty) Ltd v Lötter (supra), where the court held: 
"That document, however, is headed 'application for credit facilities' ... The application is designed to be one by a company ... all this would in my opinion clearly cause the defendant to believe that he was purporting to enter into an agreement on behalf of his company" (590F-H).

Headings may then form the basis for escaping liability based on a iustus error. The court is not often persuaded by such a reasoning but is nonetheless aware of the impact of headings (titles) of contracts as was noted above in Roomer $v$ Wedge Steel (Pty) Ltd (supra 543), where the court specifically mentioned the heading of the contract which indicated the content of the contract However, in the NCA and CPA specific mention is made of "illustrations, examples, headings or other aids to understanding" (s 64(2)(d) and s 22(2)(d) respectively).

The use of headings, preferably in a different font size or style, may be used to assist consumers in reading the contract and finding specific information which they may require (Van den Bergh 30; and Dick 1980 xviii(3) Alberta Law Review 511). All the card issuers except ABSA make very good use of explanatory headings which do make reading easier. It also breaks the mass of writing into smaller, more manageable sections, thus making it easier to find specific information. For example Standard Bank states:

\section{"1.1 Abbreviations}

Authorised Cardholder - ACH; Automated Teller Machine - ATM; Automatic Payment Order - APO; Card Division of the Bank - CD; Cardholder CARD HOLDER; Electronic Funds Transfer - EFT; Lost Card Protection - LOST CARD PROTECTION; Personal Identification Number - PIN; Secondary Cardholder - SCH; Standard Bank MasterCard Card - Card; The Standard Bank of South Africa Limited - the Bank.

\subsection{Definitions}

EFT unit - any electronic funds transfer unit in which the card or the card and a PIN can be used to initiate a transaction; merchant - the seller of goods and/or services;

purchase - any purchase effected through an EFT unit or made telephonically or by voucher;"

\section{$5 \quad$ Linguistic readability}

The conditions of use deal with "legal matters" and make use of "legal language". For the average consumer this grammatical formulation may be incomprehensible. It is often the grammar used in standard form contracts which acts as the greatest deterrent to consumers reading contracts (Van den Bergh 1). It is not only the reality of consumers being unable to understand but also the attitude of "why should I bother to read this since I won't understand it anyway".

When considering the syntactic formulation of contracts, Van den Bergh (31) identifies a number of factors which cause confusion and can be easily rectified by the drafter of the contract. Personal pronouns should be used, sentences should be as short as possible, legal terms and phrases should be avoided where possible and, where they cannot be, they should be explained. Verbs should be used in their active voice instead of their passive 
voice and cross references should be avoided. The NCA and CPA also make mention of these aspects under the 'vocabulary, usage and sentence structure of the text (ss 64(2)(c) and 22(2)(c) respectively).

\section{Personal pronouns}

The use of personal pronouns may assist the card holder in identifying which party is being referred to. For example in the Nedbank conditions of use:

"The card holder shall, immediately upon receipt of the card, sign the card in the space provided thereon" (clause 2.1).

This was changed to read:

"You must, immediately when you receive the card, insert your signature in the space provided thereon with a ball-point pen."

By making use of the personal pronoun "you" instead of the term "card holder" the consumer is left in no doubt as to whom the clause is referring. This is equally applicable to the card issuers:

Another example from Nedbank's conditions of use is:

"Ownership of the card vests in the bank and the card holder shall surrender the card to the bank ..." (clause 2.5).

This was changed to read:

"We are the owners of the card and, when your card account is closed for whatever reason, you must give the card back to us ..." (now clause 2.7).

\section{Reduced sentence length}

This particular factor is identified as being one of the most important aspects determining the readability of a contract (Van den Bergh 90). It is recommended that the average sentence length should be 22 words and that an average paragraph should not consist of more than 75 words (Van den Bergh 32; and Dick 1980 xviii(3) Alberta Law Review 512). Very few of the card issuers attempt to use short sentences or paragraphs. As an example, ABSA have one sentence consisting of 112 words which comprises one paragraph. Nedbank have attempted to shorten their sentences and also reduce the information given in a sentence. For example:

"By retaining and/or using the card, the card holder accepts all the terms and conditions herein contained and such acceptance shall deemed to have taken place in Johannesburg" (clause 2.2).

This was changed to read:

"2.2 If you do not want the card, you must destroy it immediately without using it and also notify us in writing thereof."

"2.3 By keeping and/or using the card you accept all the terms and conditions of use." 


\section{Legal terms}

Legal terms are seldom encountered by consumers in ordinary discourse and it is this aspect which lies at the heart of the simplification process (Van den Bergh 31; and Charrow and Charrow "Making Legal Language Understandable: A Psycholinguistic Study of Jury Instructions" 1979 Columbia Law Review 1306 1324). Where possible legal terms should be avoided or, at the least, be explained. Nedbank have made an attempt to do so. Their clause governing domicilium citandi et executandi now reads as follows:

"The physical address given by you on the application form will always be the address you have chosen where summonses, legal documents and notices can be served on you ('domicilium')" (clause 13.1).

They have not only eliminated a complicated legal term written in Latin, but also explained the meaning and legal effect of the term. Another relevant example is in Nedbank's conditions of use (clause 8.1) where they use the terms "non causa debiti", "de duobus vel pluribus" and "reis debendi" with no explanation of the meaning or effect of these terms. Nedbank has changed this and they now give the English version of "non causa debiti", namely "no cause of debt" and leave out the other two expressions. There is still no explanation of the effect of these legal terms and it would be preferable if a definition clause was used to explain the effect.

\section{Verb usage}

\section{Passive/active verbs}

Van den Bergh (31) identifies passive verbs as reducing the comprehensibility of sentences but Charrow and Charrow (1979 Columbia Law Review 1325) disagree. They argue that, although legal documents use a high proportion of passives, psycholinguistic research has produced equivocal results. They do concede that the positioning of the passive verb affects the comprehension of a sentence.

Nedbank's conditions of use had a high percentage of passives which was changed in their new conditions of use. An example is:

"The bank shall not in any way be liable to the card holder if the card is not acceptable to or dishonoured by any merchant ..." (clause 2.16).

This was changed to read as follows:

"We will not in any way be liable to you if any merchant or supplier does not accept the card ..." (now clause 2.18).

\section{Nominilisations}

A nominilisation is a noun which has been constructed from a verb. Legal texts and writers have often been criticized for using nominilisations when they could rather use an active verb (Van der Walt and Nienaber English for 
Law Students (1997) 10; and Benson "The End of Legalese: The Game is Over" 1985 New York University Review of Law \& Social Change 524). Charrow and Charrow (1979 Columbia Law Review 1321) state that nominilisations are more difficult to process because verbs and verb phrases are more basic than certain classes of nouns and they often replace entire subordinate clauses. Using verbs as nouns also increases sentence length as in order to change a verb to a noun other words become necessary to complete the change. Very often one will see the words "the" and "of" before and after the noun for example:

"We ensured the engagement of staff in the initiative with the use of lunchtime meetings."

It would be preferable to use an active verb in which case this sentence would read as follows:

"We engaged staff in the initiative by using lunchtime meetings." Or "We used lunchtime meetings to engage staff.

The conditions of use do not have any nominilisations, however, they are a common feature of legal writing as they sound more formal and official than the use of an active verb.

\section{Modal verbs}

Modal verbs do not stand alone in a sentence and are almost always used in front of a main verb (Van der Walt and Nienaber 146). According to Charrow and Charrow (1979 Columbia Law Review 1324; and see also Viljoen and Nienaber 66-67) modal verbs actually enhance a reader's comprehension, specifically "must", "should" and "may". This is one aspect which the standard-form contracts use to good effect. For example Nedbank's conditions of use read:

"You must, immediately when you receive ..." (clause 2.1; and see also ABSA clause 3).

First National Bank's conditions of use read:

"The holder shall immediately ..." (clause 1.02.1).

The reason for this increased comprehension is understandable because the modal verb is telling the card holder what to do Charrow and Charrow (1979 Columbia Law Review 1324). The card holder would be reading the contract with the intention of learning what he has to do or not do.

\section{Cross references}

According to Van den Bergh (31) the use of inter-textual cross references makes a contract more difficult to read and understand. The reader will constantly have to refer to other parts of the text in order to read and understand the part he is currently reading. All the conditions of use have inter-textual cross references but ABSA makes use of them more than the others. Clause 8.1 refers the reader back to clause 7, clause 9.1 and 9.2 
refer the reader ahead to clause 24 and clause 17 refers the reader to clause 23. Clause 17 has seven sub-clauses and the reader is also referred backwards and forwards amongst these clauses.

Reference is also made in the conditions of use to other sources such as sections 28 and 45 of the Magistrates' Court Act. No copy of these sections is given with the conditions of use and the card holder will have to research another source in order to understand the true meaning and effect of the contract. It is unlikely that any card holder will bother to do this.

\section{Conclusion}

In a country where the level of literacy is so low it is essential that the drafters of contracts accept some responsibility for making contracts more readable for consumers. South African businesses are fully aware of the difficulties which face consumers when they are entering into contracts. For most consumers it is a matter of economic necessity rather than choice and businesses are in a position to take advantage of this situation. Contracts may contain onerous clauses, are written in fine print in unintelligible language and are inaccessible for the literacy level of most South Africans. With the advent of the National Credit Act and the Consumer Protection Act businesses are now compelled to make an attempt to simplify the language and structure of their standard-form contracts to make them more readable.

In doing this it may well encourage consumers to read them and fully understand their obligations in terms of the contract. This may lead to fewer breaches of contract by consumers and fewer allegations that the contract was entered into while the consumer was unaware of some of the terms. Our courts are then also not faced with an unknown aspect. As can be seen in the numerous case examples given in this note, our courts have already been dealing with these factors but under the guise of determining whether a mistake is iustus or not. They will now have reference to legislation rather than the common law when deciding on this aspect. Simplifying the language and structure may not be a complete solution but it will certainly assist many consumers in understanding their rights and obligations in terms of a contract. 